\title{
Orientação pré-operatória da enfermeira: lembranças de pacientes
}

\section{Nurse preoperative guidance: patients' recollections}

\section{Orientación preoperatorio de la enfermera: recuerdos de pacientes}

Maria Henriqueta Luce Kruse', Miriam de Abreu Almeida"', Kátia Bica Keretzky"I, Eveline Rodrigues ${ }^{\text {IV }}$ Flávia Pacheco da SilvaV, Franciele da Silveira Schenini ${ }^{\mathrm{VI}}$, Vandréia Machado Garcia VII

\author{
' Doutora em Educação. Professora de Enfermagem da Universidade Federal do Rio Grande do Sul (UFGRS). E-mail: mkruse@hcpa.ufrgs.br. \\ "Doutora em Educação. Professora de Enfermagem da UFGRS. E-mail: maalmeida@hcpa.ufrgs.br. \\ III Enfermeira do Hospital de Clínicas de Porto Alegre. E-mail: kkeretzky@hcpa.ufrgs.br. \\ IV Enfermeira. E-mail: enileve2003@yahoo.com.br. \\ $\checkmark$ Enfermeira. Mestranda do Programa de Pós-Graduação em Enfermagem da UFGRS. E-mail: flavia-pf@hotmail.com. \\ VI Enfermeira. E-mail: franschenini@yahoo.com.br. \\ VII Enfermeira. E-mail: vandymg@yahoo.com.br.
}

\section{RESUMO}

A experiência da cirurgia é causadora de estresse e ansiedade ao paciente e sua família. A orientação pré-operatória realizada pela enfermeira diminui a insegurança desses pacientes. Nosso objetivo foi conhecer a opinião dos pacientes sobre a orientação fornecida pela enfermeira no pré-operatório em relação ao enfrentamento do período perioperatório. Trata-se de uma pesquisa exploratória descritiva, de abordagem qualitativa, onde foram entrevistados nove pacientes hospitalizados, em pós-operatório de cirurgia abdominal, no período de março a abril de 2008 . As entrevistas foram gravadas e transcritas para a análise do conteúdo. Foram estabelecidas três categorias: Agora eu não estou lembrando, mas foi coisa boa..., onde registramos que os pacientes pouco lembravam do que Ihes tinha sido dito, sendo necessários constantes estímulos para obter respostas. A segunda categoria, 0 doutor também conversou..., destaca a lembrança dos pacientes quanto a orientação do médico, o que enfatiza o poder do seu discurso. Na terceira categoria, Me cuidam muito bem, nada ficou faltando, é referido que a orientação ajudou no enfrentamento embora não se sentissem à vontade para opinar e sugerir o que poderia ser modificado na orientação. A pesquisa propõe discutir e revisar esta atividade da enfermeira.

Descritores: Cuidados pré-operatórios; Cuidados de enfermagem; Enfermagem perioperatória.

\section{ABSTRACT}

The experience of having surgery is a cause of stress and anxiety to patients and their families. The preoperative guidance given by nurses lessens the insecurity of these patients. Our objective was to find out the patients' opinions about the guidance offered by nurses in the preoperative stage in relation to facing the perioperative period. This is in the form of descriptive exploratory research with a qualitative approach. In the period from March to April of 2008, nine hospitalized patients in the postoperative abdominal surgery stage were interviewed. The interviews were recorded and transcribed for content analysis. Three categories were established: I don't remember right now, but it was a good thing..., when we registered that the patients had only a vague recollection of what they had been told; with constant stimulus being necessary to obtain answers. The second category: The doctor also talked to me..., highlights the patients' recollection of the doctor's guidance, which emphasizes the power of the doctor's words. The third category, They took great care of me, I didn't need a thing, is related to the fact that the guidance was helpful facing the situation, even though they did not feel completely at ease in giving an opinion or making a suggestion about what could be changed. The research proposes a discussion and review of this nursing activity.

Descriptors: Preoperative care; Nursing care; Perioperative nursing.

\section{RESUMEN}

La experiencia de la cirugía es causante de estrés y ansiedad al paciente y su familia. La orientación preoperatoria realizada por la enfermera disminuye la inseguridad de estos pacientes. Nuestro objetivo fue conocer la opinión de los pacientes sobre la orientación ofrecida por la enfermera en el preoperatorio con relación al enfrentamiento del período preoperatorio. Se trata de una investigación exploratoria descriptiva, de abordaje cualitativo, donde se entrevistaron nueve pacientes hospitalizados, en postoperatorio de cirugía abdominal, en el período de marzo a abril de 2008 . Las entrevistas fueron grabadas y transcritas para el análisis del contenido. Se establecieron tres categorías: Ahora no me acuerdo, pero fue algo bueno..., donde registramos que los pacientes poco recordaban de lo que se les había dicho, siendo necesarios constantes estímulos para obtener respuestas. La segunda categoría, El doctor también conversó..., destaca el recuerdo de los pacientes en cuanto a orientación del médico, lo que enfatiza el poder de su discurso. En la tercera categoría, Me cuidan muy bien, nada faltó, es referido a que la orientación ayudó en el enfrentamiento aunque no se sintiesen a gusto para opinar y sugerir lo que podría ser modificado en la orientación. La investigación propone discutir y revisar esta actividad de la enfermera.

Descriptores: Cuidados preoperatorios; Cuidados de enfermería; Enfermera en el perioperatorio. 


\section{NTRODUÇÃO}

A experiência da cirurgia é causadora de estresse e ansiedade ao paciente e sua família, pelo receio do desconhecido e pelas dúvidas e incertezas quanto ao processo de recuperação. O paciente cirúrgico apresenta ansiedade no período préoperatório, independente do grau de complexidade da cirurgia, pela desinformação sobre os acontecimentos que sucedem, bem como pelas demais situações que a internação hospitalar proporciona. Por mais simples que seja a cirurgia poderá ser acompanhada de anseios, dúvidas e medos $^{(1)}$.

$A$ ansiedade pode ser uma resposta às ameaças sentidas pelo paciente em relação ao seu cotidiano, sua integridade corporal, possíveis alterações físicas, financeiras, psicológicas, espirituais ou sociais e quanto ao resultado da cirurgia ${ }^{(2-3)}$. Além disso, a hospitalização provoca uma ruptura na vida do paciente, inserindo-o num ambiente desconhecido, o que modifica seus costumes e hábitos. Deste modo, o paciente tende a tornar-se inseguro e dependente das pessoas que o rodeiam ${ }^{(1)}$.

De acordo com autores da área(4-6), as orientações pré-operatórias realizadas pela enfermeira devem levar em consideração aspectos físicos e emocionais dos pacientes, devendo ser realizadas de maneira individualizada e focadas nas necessidades de aprendizado do indivíduo. No entanto, pensamos que essas orientações são oferecidas, muitas vezes, de maneira rápida e com intenso fluxo de informações, sem muito tempo para que 0 paciente assimile, formule perguntas relevantes e tire dúvidas em relação ao procedimento cirúrgico.

Acreditamos que quanto maior for o grau de entendimento dessas informações pelo paciente, menor será a sua ansiedade em relação à intervenção cirúrgica e, conseqüentemente, melhor será a sua recuperação. O modo como o paciente enfrenta a cirurgia pode levar a complicações que prejudicam a convalescença, podendo intensificar a morbidade no período pós-operatório ${ }^{(7)}$. Assim, o modo como cada um enfrenta a cirurgia interfere na recuperação e na readaptação à vida normal. Nestes casos, o contato e as informações da enfermeira poderão ajudar a diminuir a insegurança dos pacientes, proporcionando-lhe tranquilidade e bemestar, conforme constatado por vários autores ${ }^{(4,6,8-9)}$.

Para obter um melhor resultado na orientação é importante conhecer o que o paciente deseja saber, suas percepções e expectativas em relação ao procedimento, direcionando a orientação e levando em conta sua capacidade de assimilar a informação, identificando os significados que ele atribui à doença, à hospitalização e ao tratamento cirúrgico ${ }^{(4-6)}$. Para que o momento do cuidado seja um encontro de interação, diálogo, calma e esclarecimento é preciso que a orientação seja esclarecedora e eficiente no pré-operatório, o que requer algumas habilidades e conhecimentos da profissional a respeito das possíveis alterações e reações emocionais que pacientes podem apresentar quando submetidos a cirurgias. Esse processo contribui significativamente para a melhoria e visibilidade do cuidar, com ênfase na cientificidade, habilidades técnicas e humanismo ${ }^{(4-}$ 6).

O destaque dado ao papel da enfermeira na assistência no período pré-operatório vem sendo enfatizado há muitos anos. Em 1967 um artigo descreve as ansiedades e estresse psicológico enfrentado pelo paciente antes da cirurgia e o quanto isso influi em sua recuperação. Podemos observar essa afirmação no trecho que segue: "saber manter a comunicação e saber ouvir a fim de se inteirar da maneira como o paciente e seus familiares aceitam a hospitalização, a cirurgia e o tratamento, conhecer os receios, desejos e sentimentos são qualidades que a enfermeira deve desenvolver"(10). Esse mesmo artigo evidencia que as informações devem ser individualizadas, de acordo com a capacidade de compreensão do paciente, informando que é importante conhecer o que o paciente quer saber e ter cuidado com o uso de termos científicos. Assim, pensamos que esta prática da enfermeira tem sido pouco estudada nos últimos anos, sendo naturalizada e executada sem a preocupação de conhecer os benefícios para os pacientes.

Atuando em um hospital universitário, observamos cotidianamente que as enfermeiras têm uma intensa atividade de orientação de pacientes, objetivando proporcionar apoio emocional, atenção e informações neste momento de dificuldade ${ }^{(11)}$. A orientação pré-operatória eficaz auxilia o paciente a lidar com a cirurgia, reduz a duração da internação hospitalar, eleva a satisfação com o serviço prestado, minimiza complicações cirúrgicas e aumenta o bemestar psíquico ${ }^{(12)}$.

Tal observação nos levou a avaliar a prática da orientação pré-operatória desenvolvida, há longo tempo, pelas enfermeiras que atuam em unidades de internação cirúrgica, pois entendemos a orientação como um valioso instrumento para a humanização da assistência de enfermagem. Desta forma, nos propomos a analisar esta prática para saber se ela deve ser mantida, no que ela deve ser alterada ou aperfeiçoada ou se existe uma maneira mais eficiente de desenvolver essa atividade e, assim, atingir nossas metas ${ }^{(13)}$.

Nesse contexto, decidimos elaborar o presente estudo, cujo objetivo foi conhecer a opinião dos pacientes cirúrgicos sobre a orientação pré-operatória que receberam das enfermeiras, principalmente 
quanto à influência dessas orientações no enfrentamento do período perioperatório.

\section{METODOLOGI A}

Trata-se de uma pesquisa exploratória descritiva de abordagem qualitativa, cujo propósito é estimar o funcionamento de um programa de orientação préoperatória efetuado pela enfermeira, na perspectiva dos pacientes ${ }^{(13)}$. Para a coleta das informações entrevistamos pacientes adultos, internados em um hospital de grande porte, em unidades médicocirúrgicas, submetidos à cirurgia abdominal eletiva sob anestesia geral e que ficaram internados pelo menos quatro dias. Estes pacientes foram orientados pela enfermeira na unidade de internação, no dia que precedeu a cirurgia, conforme rotina da instituição. Os sujeitos foram selecionados intencionalmente, sendo feito o adicionamento progressivo de novos casos até a "saturação teórica", alcançada ao entrevistarmos nove pacientes, quando novas entrevistas não conduziam a um aumento significativo de informações ${ }^{(13)}$.

Os dados foram obtidos por meio de entrevista semiestruturada, uma vez que desejávamos estudar o assunto na perspectiva dos respondentes. Os relatos foram gravados, com prévia autorização dos pacientes, que assinaram o Termo de Consentimento Livre e Esclarecido, sendo o projeto de pesquisa aprovado pelo Comitê de Ética em Pesquisa da instituição (número 07-460). O sigilo e o anonimato dos entrevistados foram mantidos conforme resolução 196/96 do Conselho Nacional de Saúde. As entrevistas foram realizadas no período de março e abril de 2008, e posteriormente transcritas para possibilitar a análise de seu conteúdo.

Para a coleta de dados elaboramos questões que possibilitaram conhecer o nível de compreensão das orientações e permitiram que o paciente manifestasse sua opinião quanto a questões que não foram abordadas na orientação pré-operatória. As questões que nortearam as entrevistas foram: Fale sobre as informações que você recebeu da enfermeira antes da cirurgia. Elas Ihe auxiliaram a enfrentar a cirurgia? O que você gostaria de saber a respeito da sua cirurgia que não foi abordado? O que poderia mudar nas orientações recebidas?

Os dados foram coletados em dois momentos. Primeiro foram entrevistados quatro pacientes em pós-operatório que atenderam aos critérios de inclusão. Ao realizar as primeiras entrevistas nos confrontamos com o fato de que os pacientes pouco se lembravam do que Ihes tinha sido dito, embora recordassem que haviam sido orientados. Em um segundo momento, tentando resolver este problema, decidimos que as entrevistadoras iriam acompanhar a orientação da enfermeira para que tivessem ciência do que havia sido dito para o paciente. O objetivo de acompanhar estas orientações não era avaliar a qualidade das informações prestadas, mas sim para que pudéssemos ter conhecimento do conteúdo das informações e o quanto havia sido retido ou não pelos pacientes. Ainda assim, observamos que os pacientes tiveram a mesma dificuldade de relembrar ou de contar aquilo que Ihes foi dito.

Os participantes foram identificados pela letra E, acrescido do número correspondente ao depoimento. Numeramos de 1 a 4 os entrevistados da primeira parte da pesquisa e de 5 a 9 os entrevistados da segunda. Para a análise das informações foi utilizado o método de análise de conteúdo, realizado em três momentos: pré-análise, sendo feita a leitura flutuante dos depoimentos; exploração do material, onde foi selecionada as falas dos pacientes e organizadas categorias; e tratamento dos resultados, onde foi realizada a interpretação das informações coletadas $^{(14)}$.

\section{APRESENTAÇÃO DOS RESULTADOS E DI SCUSSÃO}

Os participantes da pesquisa foram nove pacientes cirúrgicos, sendo cinco do sexo masculino. A idade dos participantes variou entre os 47 e 74 anos, sendo que os entrevistados estavam entre o 4응 e 0 7으 pós-operatório de cirurgia abdominal, hospitalizados em unidades de internação cirúrgica.

\section{Agora eu não estou lembrando, mas foi coisa boa...}

Primeiramente, foi perguntado aos pacientes se lembravam da orientação pré-operatória da enfermeira, sendo que todos responderam lembrar, apesar de pouco recordar sobre o que havia sido dito. Agora eu não estou lembrando do que ela disse, mas foi coisa boa, que me ajudou muito, mas eu não lembro exato. (E2)

Eu não me lembro do que ela falou. (E8)

Ao pedirmos para que eles falassem sobre as orientações recebidas, percebemos que as lembranças espontâneas eram bastante limitadas, sendo necessários constantes estímulos para obter respostas mais específicas. Foram citadas principalmente, informações pontuais como dieta e lavagem gástrica.

Falou que ia ser o doutor que ia fazer a anestesia, me fazer dormir. E foi só. (E3)

(...) a dieta era só um caldinho no dia anterior e as lavagens, né, ficar esperando, tomar banho de manhã, essa coisa toda. (E5)

$\mathrm{Eu}$ ia ter que tomar lavagem, que minha cirurgia era de risco, que eu ia colocar bolsa de colostomia, e que no princípio depois a minha alimentação ia ser líquida, depois sólida, que eu ia ter que ficar em jejum para fazer a cirurgia. (E6) 
Ela falou que eu ia só tomar café de manhã e depois não era para pegar nada, nem uma bala. (E7)

Um dos prováveis motivos de pouco se lembrarem das orientações recebidas pela enfermeira é a ritualização da orientação pré-operatória. Tradicionalmente, a orientação pré-operatória é feita de modo semelhante a todos, independente do paciente ou da cirurgia que será realizada. Talvez o fato de não haver preparo ou treinamento específico para realizar essa atividade educativa influencie no modo como os profissionais realizam a orientação, tornando-os pouco preparados para realizar uma orientação adequada às necessidades de cada paciente. No hospital onde foi realizada a pesquisa não há rotina institucionalizada de orientação préoperatória, sendo essa realizada conforme aprendido com as profissionais mais antigas ou aplicando os conhecimentos adquiridos na formação. Assim, os achados de uma pesquisa sobre o tema demonstram que, apesar das enfermeiras estarem envolvidas na orientação pré-operatória, isso parece ocorrer de forma não padronizada e informal, sem bases teóricas de ensino e aprendizagem ${ }^{(15)}$.

A falta de individualização das orientações pode colaborar para que os pacientes não se lembrem das informações recebidas, já que são fornecidas de maneira muito semelhante a todos. Diversos autores citam a importância dos pacientes serem avaliados individualmente, levando em conta seus valores, experiências e expectativas ${ }^{(6-7,11,16)}$. Durante as entrevistas percebemos que os pacientes são orientados passivamente, sem participação no seu aprendizado, o que pode tornar-se um fator desfavorável. Estudos demonstram também que os conhecimentos e experiências prévias das enfermeiras influenciam no padrão das informações prestadas e na forma como essas orientações são conduzidas, já que ao demonstrar confiança e experiência, o paciente sente-se mais à vontade de fazer questionamentos e sanar suas dúvidas ${ }^{(15)}$.

Outro ponto a ser considerado é a linguagem técnica utilizada pelas enfermeiras, que muitas vezes pode não ser clara, dificultando o entendimento. Além disso, uma mensagem não compreendida pode provocar aumento da ansiedade e das preocupações ${ }^{(17)}$. As orientações deveriam ser fornecidas com vocabulário simples e de maneira objetiva para facilitar a compreensão dos pacientes. Encontramos na literatura pesquisas que destacam a importância de apresentar essas informações préoperatórias também de forma escrita, que pode ser mais assimilável e memorizável, minimizando problemas de comunicação ineficaz ${ }^{(3)}$.

Entretanto, percebemos que alguns pacientes durante as entrevistas mostraram-se mais preocupados com seu estado de saúde atual, tornando difícil conversar sobre as lembranças do pré-operatório.

[...] eu tô preocupada com a dor no pós-operatório, isso vai passando, né? (E1)

[...] eu queria saber se eu tenho alguma coisa ainda ou foi tirado tudo, isso eu ainda não sei. (E2)

Essas falas mostram a importância da continuidade das orientações após o ato cirúrgico, quando os pacientes ainda permanecem com muitas dúvidas e preocupações com relação à dor, prognóstico, morte, família, emprego, entre outros. Além disso, as orientações pré-operatórias não só fornecem informações específicas do que cada paciente deve esperar durante todo período transoperatório, mas também influenciam nas atitudes e comportamentos dos pacientes em relação ao seu autocuidado no pós-operatório, permitindo que ele se sinta incluído no seu processo de recuperação ${ }^{(12)}$.

Nos achados, percebemos que experiências cirúrgicas prévias trazem maior segurança ao paciente, que já sabe o que esperar.

Isso eu já sabia, foi a mesma equipe (...) agora é só fechar. (E1)

Eu já vim com dreno da primeira, eu já sabia que ia ter dreno.(E8)

Assim, as experiências anteriores parecem favorecer o enfrentamento da cirurgia, pois os pacientes tendem a desmistificar o que acontece durante o transoperatório, período de maior medo, onde criam fantasias sobre o bloco cirúrgico, anestesia, a cirurgia e a morte ${ }^{(7)}$.

Ao perguntar aos pacientes se as orientações da enfermeira lhe auxiliaram a enfrentar a cirurgia, todos responderam afirmativamente, mesmo não se lembrando do que havia sido dito. Um dos entrevistados falou da importância de saber o que está acontecendo, mostrando que o indivíduo tenta exercer um controle sobre o ambiente onde se insere, buscando dessa forma superar o problema e reduzir a ansiedade ${ }^{(18)}$.

Ajudou na ansiedade (...), fiquei mais tranquilo, dormi, acordei mais tranquilo. (E1)

Serviu porque a gente teve aquela confiança na profissional (...), a gente vai com aquela confiança de ser bem atendido. (E4)

Sim, porque eu já fui sabendo de tudo, eu já estava preparado para o que ia acontecer no futuro, na operação. (E5)

Elas me ajudaram sim, mas eu não me lembro mais, me ajudaram bem. (E7)

As orientações são citadas como auxílio para lidar com a ansiedade do momento, tranquilidade ao saber o que vai ocorrer no período trans e pósoperatório. 
[...] se uma pessoa diz uma coisa boa, tu fica mais descansado, não precisa ficar preocupado [...] tu tá fazendo uma coisa e sabe o que ta fazendo. (E3)

[...] é bom porque tira a tensão, a gente sabe o que vai acontecer, tira as dúvidas e não vai pressionado. (E5)

Deste modo, embora não sendo capazes de falar sobre a orientação pré-operatória realizada pela enfermeira, esta é vista como algo que promove calma e tranquilidade, tornando o paciente mais corajoso e minimizando a ansiedade. A explicação prévia dos procedimentos a que o paciente será submetido promove a diminuição dos temores e apreensão antes do ato cirúrgico ${ }^{(8)}$.

\section{O doutor também conversou...}

Apesar de questionados sobre a orientação da enfermeira, muitos pacientes citam a orientação do médico, mesmo nada tendo sido perguntado sobre ele, o que reforça o "status" do médico como profissional mais qualificado, possuidor de conhecimento, já que é quem detém o poder sobre o corpo do doente no momento do procedimento cirúrgico.

O doutor também conversou. Lembro do médico, ele foi no meu quarto um dia antes e a gente teve uma conversinha. (E8)

O médico veio falar comigo também, foi muito atencioso, me explicou toda a cirurgia, disse que eu ia melhorar, ficar boa. (E9)

Historicamente a enfermagem se organizou como profissão subordinada ao trabalho do médico, pois nos hospitais da época do início da enfermagem moderna a figura do médico já estava introjetada na instituição, ocupando um espaço privilegiado. Deste modo, ao se vincular ao trabalho médico a enfermeira usufruiu seu prestígio já que havia no hospital muitos cuidadores que não tinham reconhecimento profissional, iniciando uma relação de obediência e submissão. Tais fatos talvez ajudem a explicar porque em nossa cultura o médico é visto como hierarquicamente superior à enfermeira ${ }^{(19)}$.

Por outro lado, quando questionados sobre o nome das enfermeiras, os pacientes não souberam responder.

Não lembro não, o nome não. (E3)

Ah, não estou lembrado, vi ela poucas vezes, não estou lembrado do nome. (E4)

Ah, não me lembro quem foi que disse, foi uma enfermeira. (E8)

Não lembro o nome, era uma bem querida, mas não lembro o nome. (E9)

Considerando que na instituição em estudo a enfermeira que usualmente orienta no pré-operatório nem sempre é responsável pela continuidade na assistência no pós-operatório, os pacientes tendem a não criar vínculo, não reconhecendo a enfermeira que os orienta. O vínculo entre o paciente e a enfermeira é um elo necessário, para que ocorra uma relação terapêutica entre a profissional e o paciente. Além disso, a sobrecarga de informações de diferentes profissionais de saúde durante a avaliação préoperatória pode ser um fator prejudicial, já que o paciente muitas vezes fica sem um ponto de referência a quem possa sanar suas dúvidas, além do risco potencial de serem passadas informações contrastantes e incongruentes ${ }^{(3)}$.

Dois pacientes citaram a orientação recebida pela equipe médica no ambulatório, o que reforça os achados da literatura de que o momento do préoperatório imediato torna-se crítico para o recebimento de orientações.

O médico quando eu consultei me orientou sobre tudo o que eu tinha que passar e poderia acontecer. (E2)

Primeiramente me orientou o médico lá embaixo e antes da cirurgia ela me avisou tudo aquilo de novo. (E4)

Vários autores citam que a ansiedade no momento pré-operatório pode ser um fator que dificulta a apreensão de informações, já que nesse período o paciente está preocupado com o que pode Ihe acontecer durante a cirurgia ${ }^{(3,11,17)}$. Desta forma, uma orientação de enfermagem em nível ambulatorial provavelmente ofereceria um resultado mais efetivo e individualizado.

\section{Me cuidam muito bem, nada ficou faltando...}

No decorrer das entrevistas muitos pacientes citam o quanto a equipe é atenciosa e querida. Percebemos que neste momento de fragilidade, em que ainda estão em estado de dependência, os pacientes reforçam a afetividade e competência da equipe, talvez querendo atenuar o fato de não se lembrarem do que Ihes havia sido dito.

[...] desde que eu entrei aqui o atendimento é muito bom, maravilhoso das enfermeiras. Elas me tratam muito bem, nunca fiquei com dúvidas.(E2)

[...] queridas são as enfermeiras aqui, são boas pessoas e os doutores são bons, bons doutores, atendimento bom. (E7)

Todos aqui são muito queridos e atenciosos. Me cuidam muito bem. Nada ficou faltando. (E9)

O ambiente hospitalar é desconhecido e promove insegurança, modificando os costumes e hábitos dos indivíduos, que não sabem como agir, perdendo sua autonomia e tornando-se dependentes dos profissionais para atividades da vida diária que antes resolviam sem ajuda. Esses sentimentos de solidão, medo e insegurança fazem com que busquem nas pessoas que estão mais próximas, nesse caso a equipe de saúde, não apenas a cura, mas também segurança e afeto ${ }^{(18)}$. Além disso, é possível que essa manifestação de carinho com a 
equipe seja um modo de se desculpar pelo fato de não lembrarem as orientações fornecidas, como se estivessem constrangidos de não saber responder as perguntas feitas.

Ao serem perguntados sobre o que gostariam que tivesse sido falado a respeito da cirurgia e não foi abordado, os pacientes não souberam responder, informando que sabiam tudo o que precisavam saber sobre a cirurgia, mesmo não sabendo o que lhes havia sido dito. Tal fato reforça os achados anteriores, isto é, a dificuldade de lembrar o que havia sido dito, pois dificilmente os pacientes entrevistados, em uma situação crítica como é a cirurgia, teriam todos os seus questionamentos resolvidos com a orientação pré-operatória.

Não, não lembro de nada que me surpreendesse, não nada, senão eu teria lembrado.(E2)

[...] no meu caso não tenho que reclamar, nada, tudo foi falado antes. Tudo eu estava ciente. Não tive dúvidas no momento da cirurgia. (E4)

[...] foi tudo esclarecido, falado, pelas enfermeiras, pelos médicos que me atendeu, tudo foi bem esclarecidinho. (E6)

Os relatos de dois pacientes que se mostraram surpreendidos com a extensão da ferida operatória demonstram que, apesar de não terem ficado com dúvidas sobre o processo cirúrgico, houve questões que não ficaram esclarecidas.

Achava que era um "talho" menor. (...) já to todo cicatrizado.(E1)

A cicatriz ficou grande, né, mas não tem problema, o importante é a saúde. (E9)

Os pacientes que conhecem sua cirurgia têm maior facilidade para aceitar as mudanças em seu corpo $^{(20)}$. Desta forma, pensamos que se a orientação pré-operatória fosse mais participativa, questionando os pacientes sobre seus receios e dúvidas acerca do período pós-operatório, surpresas desagradáveis como o tamanho da incisão cirúrgica, entre outras, não ocorreriam, proporcionando um pós-operatório mais tranqüilo. É importante conhecer o que o paciente deseja saber para fornecer informações de acordo com suas expectativas, não aumentando a ansiedade em relação à cirurgia. Além disso, o paciente bem instruído no pré-operatório percebe o pós-operatório como não perturbador, lembrando das orientações recebidas e associando com o momento vivenciado $^{(6)}$.

Ao final da entrevista pedimos aos pacientes que sugerissem modificações nas orientações recebidas. Apenas um paciente disse que seria melhor se houvesse mais conversa.

Eu acho que faltou mais conversa, informação né, sobre a cirurgia.(E1)

Eu não tenho idéia para ti dar, eu acho que a orientação foi boa, outras orientações eu não tenho idéia. (E5)
Não tenho sugestões, para mim foi tudo bem esclarecido. (E6)

Assim, o modo como o paciente é orientado faz com que ele seja agente passivo do ensino, não se sentindo a vontade para opinar e sugerir, colaborando com o seu aprendizado. A desvantagem destas práticas ritualísticas de orientação está na negação do paciente como agente ativo do processo, não ocorrendo o desenvolvimento de habilidades necessárias para sua participação no tratamento e recuperação ${ }^{(4,16)}$. Portanto, enfrentando um momento de estresse, não surpreende que os pacientes pouco se lembrem do que lhes foi dito.

Outra razão para a falta de sugestões e críticas sobre a orientação pode ser a preocupação dos pacientes em não afrontar a equipe, já que no pósoperatório eles permanecem sob os cuidados da enfermagem. Sendo assim, é importante que a enfermeira tenha sensibilidade para encorajar o paciente a expor seus medos e dúvidas, o que provavelmente reduzirá a ansiedade, contribuindo para uma boa recuperação pós-operatória.

\section{CONSI DERAÇÕES FI NAIS}

Esta pesquisa nos revelou que os pacientes pouco se lembraram das orientações fornecidas pela enfermeira no período pré-operatório, no entanto referiram que as orientações Ihes auxiliaram no enfrentamento da cirurgia. Muitos são os fatores que justificam esse achado, como a ritualização da orientação da enfermeira, o que gera a falta de individualização desse procedimento, a linguagem técnica utilizada que muitas vezes pode não ser entendida, bem como a pouca participação dos pacientes, que tendem a ser passivos nesse momento, embora seja importante reconhecer que a ansiedade no pré-operatório pode ser um fator que dificulta a apreensão de informações. Por outro lado, o fato das orientações do cirurgião serem lembradas reforça o prestígio desse profissional no período perioperatório.

Percebemos que os discursos e a prática de orientação pré-operatória realizada pela enfermeira pouco mudaram nas últimas décadas, se compararmos nossos achados com os da literatura, permanecendo o mesmo modo de orientar e, por consequência, as mesmas falhas. Além disso, os medos e receios dos pacientes no enfrentamento da cirurgia seguem os mesmos, apesar de todos os recursos das novas tecnologias.

Diante desses fatos, podemos concluir que a orientação verbal pode não ser efetiva, sendo prejudicada por diversos aspectos, como linguagem, falta de concentração e muitas vezes fantasias por parte do paciente. Uma das alternativas para auxiliar nesse processo é encontrar outros modos de orientar os pacientes, tais como grupos, painéis com fotos, 
vídeos, oficinas e outros. Encontramos na literatura que tais métodos, vistos como alternativos, agradam os pacientes e contribuem para o seu aprendizado. Uma orientação esclarecedora e eficiente requer conhecimento, arte e experiência, fazendo do momento da assistência um encontro de interação e diálogo.

Assim, percebemos a necessidade de novas discussões e pesquisas sobre esse tema, visando revisar e aperfeiçoar esta atividade da enfermeira. Desta forma, estamos ampliando nosso projeto para envolver pacientes que foram submetidos a artroplastia de quadril. Tais pacientes recebem a orientação da enfermeira no ambulatório e em visita domiciliar no período que antecede a cirurgia. Decidimos entrevistar esses pacientes para avaliar sua percepção com a orientação feita dias antes da cirurgia, onde supomos que ocorra interação mais efetiva entre a enfermeira e o paciente.

Os achados desta pesquisa nos levaram a avaliar as práticas que desenvolvemos, uma vez que propomos que determinadas atividades não sejam banalizadas pela repetição e ritualização que adquirem em nosso dia-a-dia. Questionar a eficácia da orientação, pensar sobre o que estamos fazendo e o modo como fazemos determinada atividade, se essa está sendo efetiva ou não, faz com que avaliemos o nosso trabalho, procurando outros modos de fazer. Acreditamos que a enfermeira é uma profissional capacitada e competente para exercer seus papéis na assistência, administração, ensino e pesquisa, portanto deve buscar transformar e qualificar seu processo de trabalho.

\section{REFERÊNCI AS}

1. Souza AA, Souza ZC, Fenili RM. Orientação préoperatória ao cliente: uma medida preventiva aos estressores do processo cirúrgico. Rev. Eletr. Enf. [Internet]. 2005 [cited 2008 abr 17];7(2):215-20. Available from: http://www.fen.ufg. br/revista/revista7_2/relato_01.htm. 2. Smeltzer SC, Bare BG. Brunner \& Suddarth: Tratamento de enfermagem pré-operatório. 10ㅇed. Rio de Janeiro: Guanabara Koogan, 2005.

3. Walker JA. What is the effect of preoperative information on patient satisfaction? $\mathrm{Br} J$ Nurs. 2007; 16(1):27-32.

4 Zago MMF, Casagrande LDR. A comunicação do enfermeiro cirúrgico na orientação do paciente: a influencia cultural. Rev Latino-am Enfermagem. 1997; 5(4):69-74.

5. Chistóforo BEB, Zagonel IPS, Carvalho DS. Procurando reeducar hábitos e costumes: o processo de cuidar da enfermeira no pré e pós-operatório de cirurgia cardíaca. Cogitare Enferm. 2006; 11(1):2527.

6. Baggio MA, Teixeira A, Portella MR. Pré-operatório do paciente cirúrgico cardíaco: a orientação de enfermagem fazendo diferença. Rev. gaúcha enferm. 2001;22(1): 122-39.

7. Fighera J, Viero VE. Vivências do paciente com relação ao procedimento cirúrgico: fantasias e sentimentos mais presentes. Revista da Sociedade Brasileira de Psicologia Hospitalar. 2005; 8(2):51-63.

8. Jorgetto GV, Noronha R, Araújo IEM. Estudo da visita pré-operatória de enfermagem sobre a ótica dos enfermeiros do centro-cirúrgico de um hospital universitário. Rev. Eletr. Enf. [Internet]. 2004 [cited 2008 mai 18];6(2):213-22. Available from: http://www.fen.ufg.br/revista/revista6 2/pdf/Orig8 visita.pdf

9. Pinto A, Pinto CB. Visita Pré-Operatória. Nursing. 1996; 9(104): 4-16.

10. Gibertoni J. Assistência psicológica ao paciente para a cirurgia. Rev. Bras. Enferm. 1967;4(2):27889.

11. Grittem L, Méier MJ, Gaievicz AP. Visita préoperatória de enfermagem: percepções dos enfermeiros de um hospital ensino. Cogitare Enferm. 2006; 11(3): 245-51.

12.0ng J, Miller PS, Appleby R, Allegretto R, Gawlinski A. Effect of a preoperative instructional digital video disc on patient knowledge and preparedness for engaging in postoperative care activities. Nurs Clin North Am. 2009;44(1): 103-15.

13. Polit DF, Hungler BP. Fundamentos de pesquisa em enfermagem. 3st ed. Porto Alegre: Artes Médicas; 1995.

14. Bardin, L. Análise de conteúdo. Lisboa: Edições 70; 1977.

15. Fitzpatrick E, Hyde A. Nurse-related factors in the delivery of preoperative patient education. J Clin Nurs. 2006; 15(6):671-7.

16. Melles AM, Zago MMF. Análise da educação de clientes/pacientes na literatura brasileira de enfermagem. Rev Latino-am Enfermagem. 1999; 7(5): 85-94.

17. Silva WV, Nakata S. Comunicação: uma necessidade percebida no período pré-operatório de pacientes cirúrgicos. Rev. Bras. Enferm. 2005; 58(6): 673-6.

18. Peniche CGP, Chaves EC. Algumas considerações sobre o paciente cirúrgico e a ansiedade. Rev Latinoam Enfermagem. 2000;8(1): 45-50.

19. Kruse MHL. Os poderes dos corpos frios: das coisas que ensinam as enfermeiras. Brasília: ABEn; 2004.

20. Ferraz AF. Análise da comunicação enfermeirapaciente em hospital geral [dissertation]. São Paulo: Escola de Enfermagem/USP; 1991. 106 p.

Artigo recebido em 12.09.08.

Aprovado para publicação em 27.05.09.

Artigo publicado em 30.09.09. 